\title{
Prevalence and Contributing Factors of Neonatal Jaundice in Neonatal Intensive Care Unit at St Paul's Hospital Millennium Medical College, Addis Ababa, Ethiopia, 2019
}

\author{
Michael Tamene Haile Helen Girma \\ Neonatal nursing department, St Paul's Hospital Millennium Medical College, Addis Ababa, Ethiopia
}

\begin{abstract}
Purpose : The aim of the study is to assess prevalence and contributing factors of neonatal jaundice among neonates admitted to neonatal intensive care unit at St. Paul Hospital Millennium Medical College, from January 1 to December 31, 2018. Addis Ababa, Ethiopia, 2019. Methods : A cross-sectional institution based retrospective study was conducted on 338 samples selected using systematic random sampling taken from a oneyear retrospective review of medical records. These neonates were admitted to neonatal intensive care unit at St. Paul Hospital Millennium Medical College from January 1 to December 31, 2018. Addis Ababa Ethiopia. Data was collected by a structured checklist format then entered and analyzed using SPSS 23. Bivariate and multivariate logistic regressions were conducted to identify contributing factors of neonatal jaundice considering $p$-value less than 0.05. Results : Among 338 total neonates enrolled under this study the prevalence of neonatal jaundice was found to be $[\mathrm{p}=45(13.3 \%), \mathrm{CI}=1.83-1.90]$. The factors which show statistically significant relationship between hyperbilirubinemia were inadequate breast feeding with $\mathrm{AOR}=30.770(\mathrm{CI}=9.974-94.929)$, followed by presence of cephalhematoma $\mathrm{AOR}=9.627(\mathrm{CI}=2.651-34.958)$ and neonatal infection or sepsis having $\mathrm{AOR}=4.690$ $(\mathrm{CI}=1.529-14.390)$, maternal age $\mathrm{AOR}=.092(\mathrm{CI}=.016-.528)$, and breast milk jaundice $\mathrm{AOR}=.026(\mathrm{CI}=.003-.206)$ both do not reach statistical significance. Conclusion : By identifying the contributing factors earlier, we may be able to modify them and reduce the need for neonatal intensive care unit admissions for Neonatal Hyperbilirubinemia.
\end{abstract}

Keywords: hyperbilirubinemia, neonates, infection, prematurity

DOI: $10.7176 / \mathrm{JHMN} / 74-03$

Publication date:May $31^{\text {st }} 2020$

\section{Introduction}

Neonatal Hyperbilirubinemia is the yellowish discoloration of the skin, sclera and mucous membranes resulting from deposition of bilirubin. It happens when a serum bilirubin greater than $85 \mu \mathrm{mol} / \mathrm{L}(5 \mathrm{mg} / \mathrm{dl}) .{ }^{1}$ In a proportion of infants, jaundice may become severe, typically with total plasma/serum bilirubin (TSB) $\geq 20 \mathrm{mg} / \mathrm{dL}$ or $342 \mu \mathrm{mol} / \mathrm{L}$, necessitating prompt hospitalization for phototherapy and/or exchange transfusion (ET) to halt potential progression to acute bilirubin encephalopathy (ABE) or kernicterus. ${ }^{2}$,

Neonatal hyperbilirubinemia $(\mathrm{NH})$ is associated with a variety of conditions. It poses a direct risk of permanent neurological sequel due to neurotoxicity resulting in hearing loss and intellectual deficits. Therefor the early identification of neonates who are at a greater risk of developing severe neonatal hyperbilirubinemia is of paramount importance to preventing brain damage ${ }^{3}$ Neonatal jaundice(NNJ) is very common and is present in $60 \%$ of term babies and up to $80 \%$ of premature babies. ${ }^{4}$ The known risk factors for the occurrence of neonatal hyperbilirubinemia are exclusive breast feeding, $\mathrm{ABO}$ incompatibility, premature birth, infection, cephalohematoma, and asphyxia. ${ }^{5}$

Even though United Nations Children's Fund (UNICEF) targets to decrease in death rates occurring at neonatal age, Global Burden of Disease (GBD) indicates that first attempt to estimate the burden of severe NNJ estimated to affect 481,000 late-preterm and term neonates annually, with 114, 000 dying and $>63,000$ surviving with moderate or severe long-term neurologic impairments. ${ }^{6,13}$ That's why we need to further research and interventions to put the alarming problem under control.

Every year approximately 10.8 million children under the age of five years die worldwide and $38 \%$ of these mortalities are said to occur in the first month of life. ${ }^{8}$ Recent global study estimates that about 1.1 million babies would develop hyperbilirubinemia with or without bilirubin encephalopathy worldwide yearly. The global burden of neonatal hyperbilirubinemia impacts mostly the world's poorest countries (low-income countries), especially in South Asia and sub-Saharan Africa. Latin America, sub- Saharan Africa and South Asia account for 4\%, 32\% and $39 \%$ of cases of extreme hyperbilirubinemia (total bilirubin exceeding $428 \mu \mathrm{mol} / \mathrm{L}$ ) respectively. ${ }^{9}$

According to a report by GBD in 2016, Lack of facilities for rapid, routine bilirubin determination or suboptimal irradiance $(<8-10 \mu \mathrm{W} / \mathrm{cm} 2 / \mathrm{nm})$ from poorly maintained phototherapy devices are levels of delay for effective intervention that result in higher rates of avoidable and potentially harmful exchange transfusion as well as bilirubin induced mortality in developing countries. It also mentions home deliveries do play a role in late detection and treatment of neonatal jaundice. ${ }^{6}$ 
In Africa, neonatal jaundice is a common pediatric problem particularly in West Africa that is associated with sickness and death. ${ }^{10}$ A study conducted in Southeast Nigeria found that neonatal jaundice accounted for $35 \%$ of hospital admissions and 9.7\% of newborns developed kernicterus. ${ }^{11}$ In Ethiopia, according to a study done in Tikur Anbessa Hospital, among 356 total neonates, 160(44.9\%) of them were diagnosed for hyperbilirubinemia. From these, $11(6.9 \%)$ neonates developed bilirubin encephalopathy. ${ }^{12}$

As the above studies indicate bilirubin induced mortality is highly prevalent in developing countries, in which our country belongs to. So the main aim of our study is to determine its prevalence and factors leading to this problem in SPHMMC and to look ways to decrease associated morbidity, severe complications and mortalities which can easily be treated only if identified and treated earlier.

Neonatal jaundice is among the leading causes of neonatal morbidity and mortality in Ethiopia. ${ }^{12}$ Even though neonatal jaundice is not totally preventable, with early detection and treatment it is possible to avert irreversible complications. There are limited studies done in Ethiopia on neonatal Jaundice. Therefore, this study focused on the assessment of recent prevalence of neonatal jaundice and factors contributing in NICU of SPHMMC, which help for better preparedness and resource allocation in the unit. The study findings also can help policy makers and other sectors working on neonatal health to plan for early detection and treatment. The study also helps as a scientific reference for further related studies.

\section{Material and methods}

Study area, period and design

Institution based, retrospective cross-sectional study was conducted among neonates admitted to neonatal intensive care unit (NICU) from January 1 to December 31, 2018 at St Paul's Hospital Millennium Medical College (SPHMMC)., Addis Ababa, Ethiopia The study was conducted on the period of July 1- July 15, 2019 using a oneyear retrospective data.

\section{Source Population}

The source population includes all neonates admitted to NICU of SPHMMC from January 1 to December 31, 2018. Study population

All randomly selected neonates admitted to NICU of SPHMMC during the study period.

\section{Sample Size and Sample Size Determination}

Sample size for the study was determined by using single population formula, by taking the proportion of previous similar study conducted at Tikur Anbessa hospital, Addis Ababa, 2018. ${ }^{12}$ Sample size is calculated by using single population proportion formula by taking the proportion (p) of $44.9 \%$, with $\mathrm{CI}=95 \%$, margin of error $=0.05$ with a correction formula used to determine the sample size.

So, $\mathbf{n}_{\mathbf{f}}=\mathbf{3 3 8}$.

Sampling Technique

To sort out our final sample participants $\mathbf{n}_{\mathbf{f}}=\mathbf{3 3 8}$, we used systematic random sampling with a formula $K=N / n$ where,

$\mathrm{N}=$ the total number of neonates admitted to NICU during the study period, and $\mathrm{n}=$ the population under study as, $\mathrm{K}=3067 / 338=9$

As $\mathrm{K}=$, we selected every 9 th chart and found 338 charts to be reviewed, after selecting the first serial number using a lottery method.

\section{Operational definitions}

- Neonatal jaundice: is a yellowish discoloration of a newborns skin and eyes.

- Fetal Asphyxia: A complete lack or inadequate supply of oxygen by a baby before birth.

- Breast Milk Jaundice: Jaundice due certain substance in breast milk which blocks bilirubin breakdown.

- $\quad$ Breast Feeding Jaundice: Jaundice caused by inadequate intake of breast milk.

Eligibility Criteria

Inclusion criteria

All neonates admitted in NICU of SPHMMC between January 1 to December 31, 2018, with complete documentation of History, physical examination and management.

\section{Exclusion Criteria}

All neonates admitted in NICU of SPHMMC between September 1 and August 30 with incomplete documentation of History, physical examination and management.

Data collection methods

Data was collected using check list prepared by Investigators after reviewing related literatures. It has four parts which was filled by reviewing chart of medical records of patients. The checklist had parts to be completed as sociodemographic characteristics, maternal information, and neonatal information. It also contains associated medical information of the newborn which helps to trace related factors.

Data quality assurance

The quality of data was assured by using careful data collection procedures which was checked by supervisors for 
completeness, consistency and accuracy. Pretest was conducted on $5 \%$ of the sample before the actual data collection period. Corrective measures were taken, when necessary by the research team, to ensure a common understanding of each record.

\section{Data processing and Analysis}

Data was entered into SPSS 23 after checking for completeness then analyzed and expressed using descriptive methods and logistic regression was applied to sort out relationship between variables. Using binary logistic regression variables were identified for having association $(\mathrm{p}<0.05)$ with neonatal jaundice and these significant factors were further analyzed with multivariate logistic regressions to find out a statistically significant association.

\section{Ethical Considerations}

Ethical clearance was obtained from St Paul's Hospitals Millennium Medical College Institutional Review Board to conduct the research. Since the study is record review confidentiality about patient profile and other ethical aspects were strictly maintained throughout the study and then after. Additional Consent was also granted from the appropriate personnel in the record office.

\section{Results}

\section{Socio demographic characteristics of the study population}

The study population consisted of $338(n=338)$ neonates admitted in St. Paul Hospital Millennium medical college. The study involved a one-year retrospective record review. Out of the 338 cases analyzed, $252(74.6 \%)$ were males. Most of births is through spontaneous Vaginal delivery, $274(81.1 \%)$ Majority of the neonates had no infection $310(91.7 \%)$ (Table 1).

Table 1: Socio-demographic and clinical characteristics of the study population at SPHMMC, 2018

\begin{tabular}{|lll|}
\hline \multirow{3}{*}{ Characteristics } & Category & Number $(\%)$ \\
\hline \multirow{3}{*}{ PPROM } & Primigravida & $118(34.9 \%)$ \\
\cline { 2 - 3 } & Multigravida & $220(65.1 \%)$ \\
\hline \multirow{3}{*}{ Mode of delivery } & No PPROM & $313(92.6 \%)$ \\
\cline { 2 - 3 } Newborns sex & Had PPROM & $25(7.4 \%)$ \\
\hline \multirow{3}{*}{ Gestational age } & Cesarean section & $48(14.2 \%)$ \\
\cline { 2 - 3 } & Spontaneous vaginal & $274(81.1 \%)$ \\
\cline { 2 - 3 } & Instrument assisted & $16(4.7 \%)$ \\
\hline \multirow{2}{*}{ Infection } & Male & $252(74.6 \%)$ \\
\cline { 2 - 3 } & Female & $86(25.4 \%)$ \\
\cline { 2 - 3 } & Preterm $(<37$ wks) & $317(93.8 \%)$ \\
\cline { 2 - 3 } & Term (37-42 wks.) & $13(3.8 \%)$ \\
\cline { 2 - 3 } & Post term (>42 wks.) & $310(91.7 \%)$ \\
\cline { 2 - 3 } & No infection & $28(8.3 \%)$ \\
\hline
\end{tabular}

\section{Maternal Age}

The age of mothers is highly concentrated around the age 25-29 years which were 156 (46.25\%) (Figure 1).

Figure: 1 Maternal age distribution who delivered at SPHMMC in 2018.

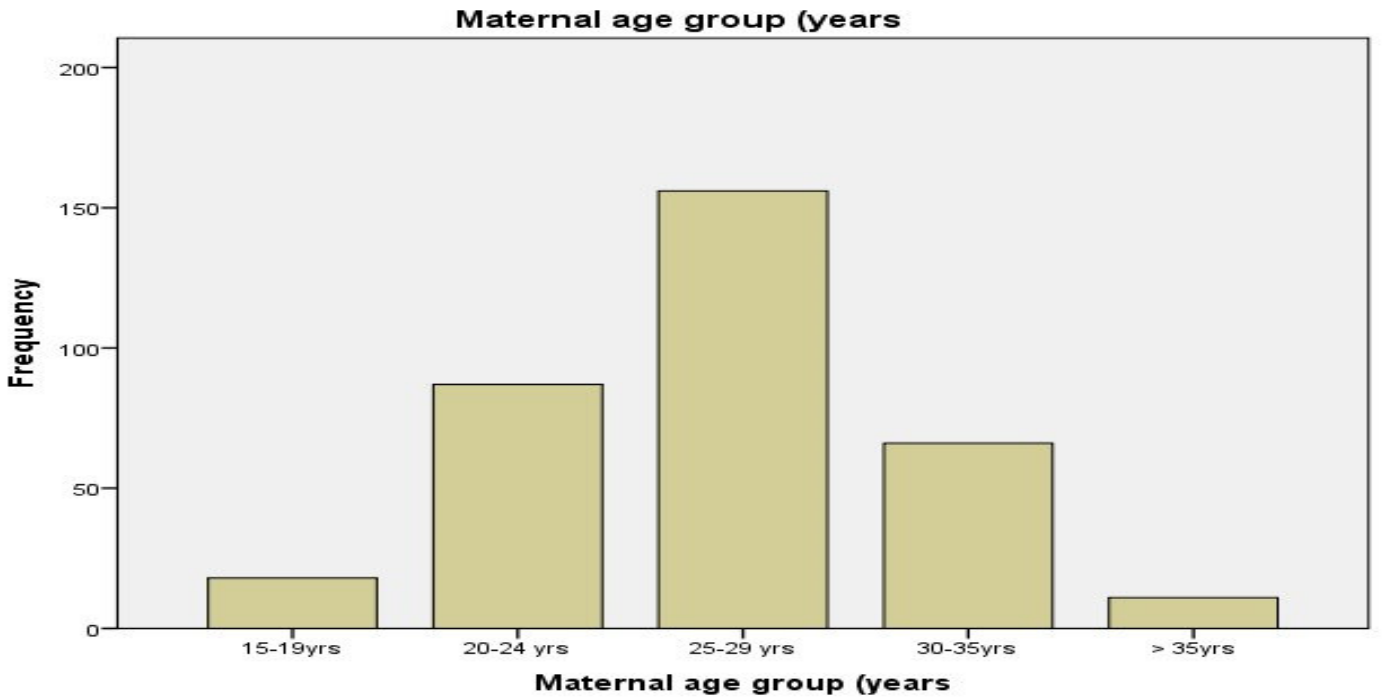




\section{Prevalence of neonatal jaundice}

The finding of this study shows that the prevalence of neonatal jaundice is $[\mathrm{p}=13.3 \%(\mathrm{CI}=1.83-1.90)]$, which were diagnosed and confirmed by laboratory to have a raised bilirubin level (Figure 2).

Figure: 2 Prevalence of neonatal jaundice among neonates admitted at SPHMMC in 2018.

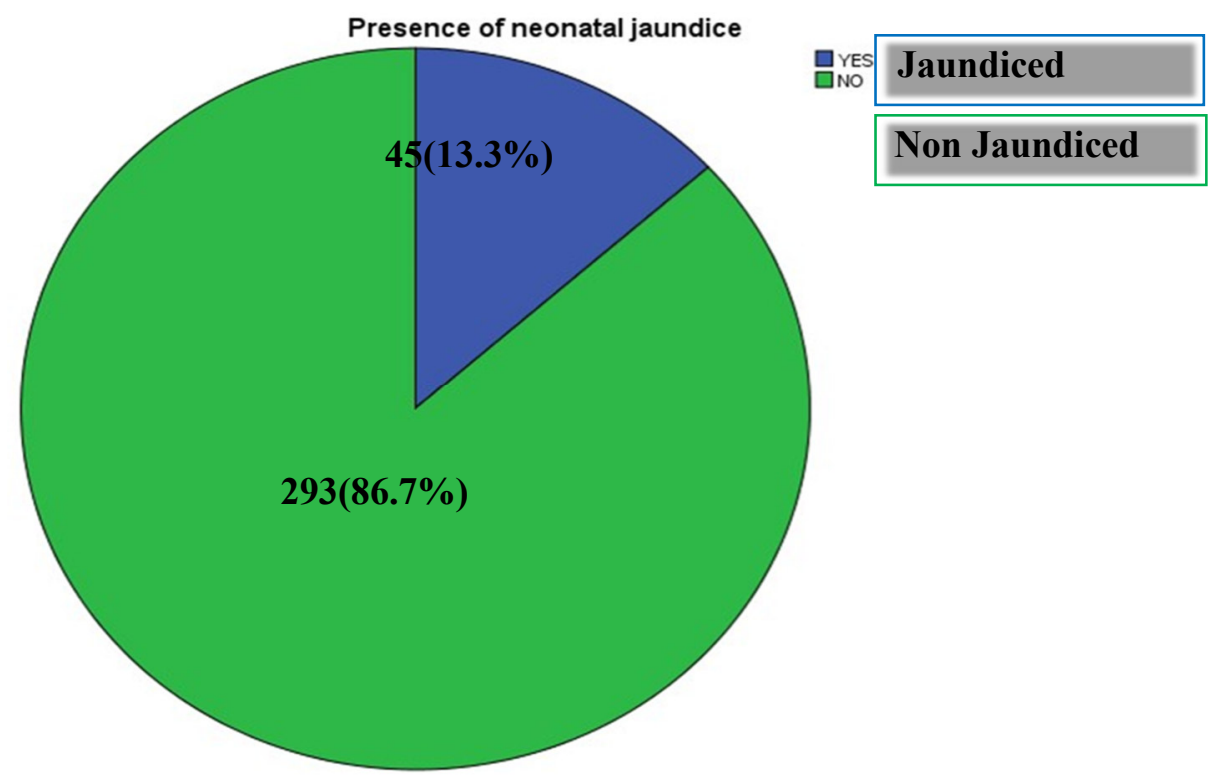

Contributing factors of Neonatal Jaundice

Maternal age, infection, inadequate breast feeding, cephalhematoma and breast milk jaundice were included in the final model for the contributing factors of neonatal jaundice. The multivariate logistic regression reveled that inadequate breast feeding (breast feeding jaundice) $\mathrm{AOR}=[30.770$ (9.974-94.929)] is the major contributor for neonatal jaundice followed by cephalhematoma $\mathrm{AOR}=[9.627(2.651-34.958)]$ and neonatal infection having an $\mathrm{AOR}=[4.690(1.529-14.390)]$. Conversely, maternal age group of 30-35 years $\mathrm{AOR}=[0.092(.016-.528)]$ and 2529 years $\mathrm{AOR}=[0.250(.070-.900)]$ have less likelihood of contributing to neonatal jaundice. The other factors such as breast milk jaundice $[\mathrm{AOR}=.026(.003 .206)]$ and maternal age $[\mathrm{AOR}=.092(.016-.528)]$ do not reach statistical significance level (Table 2).

Table 2: Contributing factors of neonatal jaundice in NICU at SPHMMC, 2018

\begin{tabular}{|c|c|c|c|c|c|c|}
\hline $\mathrm{S} / \mathrm{N}$ & Variable & Jaundice & & $\mathrm{COR}(95 \% \mathrm{CI})$ & $\operatorname{AOR}(95 \% \mathrm{CI})$ & PV \\
\hline \multirow{6}{*}{1} & Maternal Age & No & Yes & & & \\
\hline & 15-19 Years & $13(3.8 \%)$ & $5(1.5 \%)$ & 0.0 & 0.0 & \\
\hline & 20-24 Years & $72(21.3 \%)$ & $15(4.4 \%)$ & $.542(.168-1.748)$ & $.356(.092-1.373)$ & .134 \\
\hline & 25-29 Years & $139(41.1 \%)$ & $17(5.0 \%)$ & $.318(.101-1.002)$ & $.250(.070-.900)^{*}$ & .034 \\
\hline & 30-35 Years & $61(18.0 \%)$ & $5(1.5 \%)$ & $.213(.054-.844)$ & $.092(.016-.528)^{*}$ & .007 \\
\hline & Above 35 Years & $8(2.4 \%)$ & $3(0.9 \%)$ & $.975(.182-5.235)$ & $.565(.069-4.643)$ & .596 \\
\hline \multirow{3}{*}{2} & Infection & & & & & \\
\hline & No & $278(82.2 \%)$ & $32(9.5 \%)$ & 0.0 & 0.0 & \\
\hline & Yes & $15(4.4 \%)$ & $13(3.8 \%)$ & $.133(.058-.304)$ & $4.690(1.529-14.390)^{*}$ & .007 \\
\hline \multirow[t]{3}{*}{3} & $\begin{array}{l}\text { Inadequate Breast } \\
\text { feeding }\end{array}$ & & & & & \\
\hline & No & $288(85.2 \%)$ & $26(7.7 \%)$ & 0.0 & 0.0 & \\
\hline & Yes & $5(1.5 \%)$ & $19(5.6 \%)$ & $42.094(14.529-121.950)$ & $30.770(9.974-94.929)$ ** & .000 \\
\hline \multirow[t]{3}{*}{4} & Cephalhematoma & & & & & \\
\hline & No & $285(84.3 \%)$ & $37(10.9 \%)$ & 0.0 & 0.0 & \\
\hline & Yes & $8(2.4 \%)$ & $8(2.4 \%)$ & $9.627(2.651-34.958)$ & $9.627(2.651-34.958) *$ & .001 \\
\hline \multirow{3}{*}{5} & Breast Milk Jaundice & & & & & \\
\hline & No & $291(86.1 \%)$ & $41(12.1 \%)$ & 0.0 & 0.0 & \\
\hline & Yes & $2(0.6 \%)$ & $4(1.2 \%)$ & $.070(.013-.397)$ & $.026(.003-.206)$ & .001 \\
\hline
\end{tabular}

*: Significant association at $\mathrm{p}$-value $<0.05, * *$ : Significant association at $\mathrm{p}$-value $<0.001$

\section{Discussion}

The findings of this study revealed that the prevalence of neonatal jaundice is $[\mathrm{p}=13.3 \%(\mathrm{CI}=1.83-1.90)]$ which is much lower than similar studies conducted on the magnitude at Black Lion specialized Teaching Hospital which 
was $44.9 \%$ and another study at Mekelle city, both in Ethiopia public hospitals, reported the prevalence of neonatal jaundice to be $37.3 \%$. Additionally, Africa studies of south east Nigeria and Kenyan district hospital both report relatively higher prevalence of $35 \%$. This variation might be linked with the fact that differences do appear among study designs and study areas we have selected for the study.

The contributing factors identified in this study were inadequate breast feeding (breast feeding jaundice) $[\mathrm{AOR}=30.770$ (9.974-94.929)] meaning inadequately fed infants have thirty times likelihood developing neonatal jaundice than well fed infants, followed by cephalhematoma [AOR=9.627(2.651-34.958)], showing babies having cephalhematoma after instrumental delivery are nine fold at risk of developing jaundice than without cephalhematoma, and neonatal infection or sepsis having an $[\mathrm{AOR}=4.690$ (1.529-14.390)], demonstrating neonates with infection or sepsis are four times likely to have jaundice than those who don't have sepsis.

Institution based cross-sectional study conducted from February to April 2016 at Mekelle city public hospitals states that the odds of neonatal jaundice among neonates who had sepsis was 2.6 times higher compared with those neonates without sepsis $[\mathrm{AOR}=2.64 ; 95 \% \mathrm{CI}(1.15-6.05)]$ which had comparable result with the finding of this study, neonatal infection or sepsis having an [AOR=4.690 (1.529-14.390)].

The etiologic factors of Neonatal Hyperbilirubinemia according to the study at Black Lion Hospital are ABO Incompatibility (35.6\%), sepsis (18.8\%), breast feeding $(10 \%)$ and Prematurity $(8.1 \%)$. Breast feeding jaundice demonstrated a strong significant association in our study $[A O R=30.770(9.974-94.929)]$ which comprises $10 \%$ of the etiologic factors of the study at Black Lion Hospital, Ethiopia.

In the similar cross-sectional study done on national district hospital, Bloemfontein, South Africa normal vaginal delivery was the only risk factor associated with neonatal jaundice even if the majority of babies included in this study were born via C-section (64.6\%). Normal vaginal delivery was associated with neonatal jaundice statistically, $(p=0.04)$ and the use of oxytocin was not associated with a higher incidence of neonatal jaundice ( $p$ $=0.44)$ ] which is seen in our study that shows spontaneous vaginal delivery having significant association during bivariate analysis with neonatal jaundice $[\mathrm{P}=.007, \mathrm{CI}=(1.319-6.011)]$ and also oxytocin use $[\mathrm{P}=.036(\mathrm{CI}=1.055-$ $5.150)]$ though both do not reach statistical significance during multivariate analysis.

\section{Conclusion}

As the findings of this research indicate, the prevalence of neonatal jaundice was found to be $13.3 \%$ and the major contributors were breast feeding jaundice followed by cephalhematoma and neonatal infection. So effort has to be made to decrease the prevalence of neonatal jaundice due these preventable factors.

\section{Acknowledgments}

First of all, we would like to thank almighty God for giving us the strength and patience throughout the study period. Next we would like to be grateful to our colleagues Elsabeth workneh and Fedila Mohammed for their help during the whole process. Then we would like to express our respect to SPHMMC Administrative, who gave us the permission to proceed and NICU department, for their support in providing all the necessary information. Finally, we would like to be grateful to all who had been supporting us both with idea and logistics.

\section{Disclosure}

The author reports no conflicts of interest in this work.

\section{References}

1. Layer BJ, Spector ND. Hyperbilirubinemia in the newborn. Philadelphia. Drexel University College of Medicine Rev 32: 341. 2. 2., (2011) https://www.ncbi.nlm.nih.gov/pubmed/21807875

2. The Young Infants Clinical Signs Study Group. Clinical signs that predict severe illness in children under age 2 months: a multicenter study. Lancet 2008; 371:135-142. Pmid: 18191685. https://www.ncbi.nlm.nih.gov/pubmed/18191685

3. Herbst H. The prevalence of neonatal jaundice. Afri J Prim Health Care Fam Med.. Britsh. 1582 https://www.ncbi.nlm.nih.gov/pubmed/29781686 2018; 10(1):

4. M Kaplan et al. Imbalance between production and conjugation of bilirubin. Israel. Faculty of Medicine of Herbew University. 2002 https://www.ncbi.nlm.nih.gov/pubmed/12359820. 110(4):e47

5. Ching-Shan et al. Neonatal jaundice and molecular mutations. Taipie, Tiawan. American Journal of Hematology. January 1996. https://doi.org/10.1002/(SICI)10968652(199601)51:1<19::AIDAJH4>3.0.CO;2-A. 19-25

6. Olusanya BO, Teeple S, Kassebaum NJ. The Contribution of Neonatal Jaundice to Global Child Mortality: Findings from the GBD 2016 Study. Pediatrics. 2018;141(2): e20171471

7. Janet Rennie et al. Neonatal jaundice: summary of NICE guidance. England. Elizabeth Garrett Institute of women health. May 2010. https://scholar.google.com/scholar. 340

8. B. O. Olusanya et al. Infants with severe neonatal jaundice. Nigeria. University of Lagos. 2009. 
https://doi.org/10.1111/j.1365-3156.2009.02223.x. :14: 301-310

9. Vinod K. Bhutani et al. Neonatal hyperbilirubinemia and Rhesus disease of the newborn. Pediatric Research. 2010. https://www.nature.com/articles/pr2013208. 74:86-100

10. HE Chime et al. Prevalence of neonatal jaundice. Nigeria. International journal of health research. 2012 . https://www.ajol.info/index.php/ijhr/article/view/82097. :4:123-126

11. Michael Sgro et al. Incidence and causes of severe neonatal hyperbilirubinemia. Canada. Canadian Medical Association Journal. 2006. http://www.cmaj.ca/content/175/6/587.short. 175:587-590.

12. Kassa et al. Neonatal Hyperbilirubinemia: Magnitude and Associated Etiologic Factors among Neonates. Ethiopia. J Preg Child Health. 2018. https://pdfs.semanticscholar.org > ... 4-5.

13. United Nations Children's Fund (UNICEF). The State of the World's Children 2016. A Fair Chance for Every Child. New York, NY: United Nations Children's Fund (UNICEF); 2016

14. Slusher TM et al. Burden of severe neonatal jaundice. USA. University of Minnesota. 2017. https://www.ncbi.nlm.nih.gov/pubmed/29637134. 10:1136

15. Ayenew Engida Yismaw et al. Survival and predictors among preterm neonates. Ethiopia. Italian Journal of Pediatrics. 2019. https://www.ncbi.nlm.nih.gov/pmc/articles/PMC6322326/. 45:4

16. Central statistics agency. Ethiopian Demographic and Health Survey. Ethiopia. The DHS Program ICF Rockville, Maryland, USA. 2016. https://dhsprogram.com/pubs/pdf/FR328/FR328.pdf.

17. Chavan NN et al. Accidental haemorrhage in third trimester. India. International Journal of Reproduction, Contraception, Obstetrics and Gynecology. Rev. 2019. https://www.ijrcog.org > index.php > ijrcog > article > download. : 198-202

18. Shilongo SN et al. Prevalence of Critical Bilirubin Results among Neonatal Patients. Namibia. SM Journal of Family Medicine. 2017. https://www.researchgate.net > publication > 317035408_Shilongo_SN_Muk. $1: 1001$.

19. MAY-JEN HUANG et al. Risk Factors for Severe Hyperbilirubinemia. Taiwan. Fooyin University. 2004. ttps://www.nature.com/articles/pr2004574.pdf?origin=ppub. 151

20. Ehsan Garosi et al. The Relationship between Neonatal Jaundice and Maternal and Neonatal Factors. Iran. $\begin{array}{llll}\text { Iranian } & \text { Journal } & \text { of } & \end{array}$ http://eprints.mums.ac.ir/2133/1/IJN_Volume\%207_Issue\%201_Pages\%2037-40.pdf. 38-39

21. Eyasu A. Lake et al. Magnitude of Neonatal Jaundice and Its Associated Factor. Mekele. International Journal of Pediatrics. 2019. https://www.hindawi.com/journals/ijpedi/2019/1054943/.

22. C. N. Onyearugha et al. Neonatal Jaundice: Evaluating the Knowledge and Practice of Expectant Mothers. $\begin{array}{lllll}\text { Nigeria. Journal of Health } & 2016 .\end{array}$ http://www.informaticsjournals.com/index.php/jhsr/article/view/4918 